\title{
La constitucionalización del arbitraje en el Perú: algunas consideraciones en torno a la relación del arbitraje con la Constitución, los derechos fundamentales y el Estado de derecho
}

\section{Constitutionalization of arbitration in Peru: some \\ considerations around relationship among arbitration, Constitution, fundamental rights and Rule of law}

\author{
REYNALDO BUSTAMANTE ALARCÓN*
}

\begin{abstract}
Resumen: El artículo toma como punto de partida el enriquecimiento progresivo por el que ha transitado la concepción de derechos fundamentales, que actualmente no solo implican el otorgamiento a sus titulares derechos, libertades, competencias e inmunidades sino que todos - Estado y particulares - estamos obligados a respetarlos, defenderlos, garantizarlos y promoverlos, independientemente de que su titular haya desplegado o no una conducta con ese propósito. A partir de ello, el autor analiza la definición y principales características del arbitraje, destacando su dimensión constitucional y proponiendo una lectura sistemática y en armonía con los derechos fundamentales.
\end{abstract}

Palabras clave: arbitraje - jurisdicción - Constitución - derechos fundamentales - Estado de derecho - debido proceso - arbitrariedad razonabilidad

Summary: This article point out the progressive enrichment by which fundamental rights concept have gone through, providing to holders - government and individuals - not only rights, liberties, powers and immunity but also the obligation to respect, defend, guarantee and promote all them regardless the conduct displayed by the holder in this field. With this in mind, the author examines arbitration definition and main characteristics, highlighting its constitutional dimension proposing a systematic reading in accordance with fundamental rights.

Key words: arbitration - jurisdiction - constitution - fundamental rights Rule of law - due process - arbitrariness - reasonableness

\footnotetext{
* Abogado en Perú y España. Doctor en Derecho por la Universidad Carlos III de Madrid. Graduado del posgrado en Derecho Español por la Universidad Alcalá de Henares, así como de la maestría en Derecho Constitucional y de la licenciatura en Derecho por la Pontificia Universidad Católica del Perú. Profesor del Departamento de Derecho, de la Escuela de Posgrado y del Instituto de Democracia y Derechos Humanos de esta casa de estudios. Profesor del Departamento de Derecho de la Universidad del Pacífico. Investigador y profesor invitado de la Universidad Carlos III de Madrid y de otras universidades nacionales y extranjeras. Artículo elaborado en Lima, Perú. Correo electrónico: reynaldo@bustamanteasociados.com
} 


\section{INTRODUCCIÓN}

La segunda parte del artículo 139, inciso 1, de la Constitución peruana señala: «No existe ni puede establecerse jurisdicción alguna independiente, con excepción de la militar y la arbitral». Resulta pertinente indagar entonces sobre las consecuencias de esta recepción constitucional del arbitraje, teniendo en cuenta el valor que la Constitución ostenta en el pensamiento jurídico de nuestro tiempo y su relación con otras instituciones igualmente importantes, como el Estado de derecho y los derechos fundamentales (las implicancias sobre la justicia militar no corresponden al ámbito material de este trabajo).

Sabido es que la concepción sobre la Constitución y sus implicancias para el derecho no han sido siempre las mismas. La historia del pensamiento jurídico lo confirma ${ }^{1}$. Hoy en día, el derecho occidental y moderno se edifica a partir de una concepción principal — denominada constitucionalismo o neoconstitucionalismo-, según la cual la Constitución no es solo un código político que funda el Estado e instituye el ordenamiento jurídico, sino también un conjunto de normas fundamentales con propia fuerza jurídica de la mayor jerarquía. Es decir, en el derecho de nuestro tiempo la Constitución aparece como la norma fundamental, que además de fundar el Estado y el ordenamiento jurídico en su conjunto, es al mismo tiempo el principal criterio de validez de las demás normas jurídicas: todas las normas del ordenamiento deben crearse, interpretarse y aplicarse de conformidad con la Constitución. Si no resultan conformes con ella, las normas jurídicas, sean públicas o privadas, resultarán inválidas.

Al mismo tiempo, su propia fuerza normativa hace que la Constitución resulte directamente aplicable, sin necesidad de que exista una norma que desarrolle o complemente su contenido (una cosa es que el legislador pueda desarrollar el contenido constitucional y otra muy distinta que ese desarrollo sea imprescindible para que la Constitución rija y surta efectos jurídicos). Por su importancia, el constitucionalismo plantea además la existencia de una protección jurisdiccional de la Constitución, tanto para velar por la constitucionalidad normativa como para hacer frente a las conductas de diverso tipo que la amenacen o vulneren (es el caso,

1 Ver: FIORAVANTI, Maurizio. Constitución: de la antigüedad a nuestros días. Segunda reimpresión. Madrid: Trotta, 2011. 
por ejemplo, de los procesos de inconstitucionalidad, de habeas corpus y amparo, etc. $)^{2}$.

La concepción sobre el Estado de derecho también ha pasado por una evolución similar. Hemos pasado de una concepción sobre el Estado legal de derecho a otra sobre el Estado constitucional de derecho, una diferencia terminológica que encierra una distinción conceptual: mientras el Estado legal de derecho se conforma con que el poder actúe sujeto a la ley, sin poner el acento en cuál pueda ser su contenido, el Estado constitucional de derecho exige que el poder actúe conforme a la ley, pero no a cualquier ley, sino conforme a una que sea compatible con cierto contenido de justicia previsto en la Constitución. Digamos que, mientras en el primer tipo de Estado basta con que el poder se sujete a ciertas exigencias formales (que haya sido ejercido por el órgano competente y a través del procedimiento previamente establecido), en el segundo se requiere, además, que actúe conforme con el contenido de justicia constitucionalmente previsto ${ }^{3}$.

Si a eso se agrega que este contenido varía en función de si estamos ante un Estado liberal o uno social o un Estado democrático de derecho, las distintas posibilidades de configuración estatal y de su actuación son muy amplias y pueden llegar a ser muy distintas entre sí (como muestra una señal: mientras el Estado liberal suele no considerar como derechos

2 Ver: «Formas de (neo)constitucionalismo: un análisis metateórico». Isonomía, Revista de Teoría y Filosofía del Derecho, 16 (abril de 2002), pp. 97-101. Ver también la réplica de José Juan MORESO: "Comanducci sobre neoconstitucionalismo". Isonomía, Revista de Teoría y Filosofía del Derecho, 19 (octubre de 2003), pp. 267-282.

3 Cf.: FerRAJOLI, Luigi. «Pasado y futuro del Estado de derecho». En VV.AA. Neoconstitucionalismos. Colección Estructuras y Procesos, edición de Miguel CARBONELL, traducción de Pilar Allegue. Madrid: Trotta, 2003, pp. 13-29. Hay quienes plantean una ruptura entre la concepción del Estado (legal) de derecho y la del Estado constitucional, pues consideran a este último como un modelo diferente que rompe definitivamente con el anterior (es el caso, por ejemplo, de Gustavo ZAGREBELSKY en El derecho dúctil: ley, derechos, justicia, traducción de Marina Gascón. Madrid: Trotta, 1995), y quienes, por el contrario, consideran que no hay tal ruptura sino una simple evolución, donde el Estado constitucional aparece como un modelo superior del Estado (legal) de derecho (ver, entre otros, a PECES-BARBA, Gregorio. «Desacuerdos y acuerdos con una obra importante». Derechos sociales y positivismo jurídico. Escritos de filosofía jurídica y política. Cuadernos Bartolomé de las Casas, 11, Instituto de Derechos Humanos Bartolomé de las Casas, Universidad Carlos III de Madrid. Madrid: Dykinson, 1999, p. 125). Para los primeros hay una ruptura porque, desde su punto de vista, la supremacía constitucional, que es consustancial al Estado constitucional, hace que los principios constitucionales vayan directamente a los jueces, y que los jueces, sobre la base de estos principios, interpreten de alguna manera, e incluso modifiquen las leyes, sin necesidad del procedimiento de control de constitucionalidad. Una situación que no es posible en el Estado (legal) de derecho. En cambio, para los segundos tal concepción produce en la práctica un activismo judicial exacerbado, que se convierte en una severa patología cuando los órganos jurisdiccionales toman decisiones o se inmiscuyen en áreas cuya regulación corresponde a los otros poderes del Estado. Por eso estos últimos defienden la coexistencia entre un Parlamento representativo que produce leyes y unos Tribunales de Justicia que crean derecho, ambos sometidos a la Constitución, aunque con la primacía del primero por ser representante de la soberanía popular. Un planteamiento que postula la integración entre la Constitución y la ley para restablecer el equilibrio entre los productos normativos del Parlamento y del derecho judicial, según sus respectivos ámbitos de competencia. Es en este segundo sentido que el Estado constitucional se presenta como la evolución -y no como la rupturadel Estado (legal) de derecho, dotado de un contenido material (verbigracia, el Estado liberal, social o democrático de derecho), al que se le ha incorporado la idea de supremacía constitucional y la protección jurisdiccional de la Constitución. Es este segundo sentido el que utilizaremos en el presente trabajo al referirnos al Estado de derecho, o al Estado constitucional, en su evolución actual.

LA CONSTITUCIONALIZACIÓN DEL ARBITRAJE EN EL PERÚ: ALGUNAS CONSIDERACIONES EN TORNO A LA RELACIÓN DEL ARBITRAJE CON LA CONSTITUCIÓN, LOS DERECHOS FUNDAMENTALES Y EL ESTADO DE DERECHO

CONSTITUTIONALIZATION OF ARBITRATION IN PERU: SOME CONSIDERATIONS AROUND RELATIONSHIP AMONG ARBITRATION, CONSTITUTION, FUNDAMENTAL RIGHTS AND RULE OF LAW 
fundamentales al acceso a la vivienda y a la sanidad pública, el Estado social los tendrá como derechos fundamentales imprescindibles para la satisfacción de las necesidades básicas de las personas) ${ }^{4}$.

La concepción de los derechos fundamentales también se ha enriquecido. Hoy no solo son concebidos como derechos subjetivos básicos de las personas para que cada una de ellas pueda alcanzar el máximo desarrollo posible de todas las dimensiones de su dignidad (la llamada dimensión subjetiva de los derechos), sino también como los elementos esenciales de todo ordenamiento jurídico que se precie de ser justo o, si se prefiere, de pertenecer a una sociedad bien ordenada: libre, abierta, plural y democrática (la llamada dimensión objetiva de los derechos).

Como consecuencia de ello, los derechos fundamentales no solo otorgan a sus titulares derechos, libertades, competencias e inmunidades cuyo respeto y realización pueden exigir, sino que todos - Estado y particulares- estamos obligados a respetarlos, defenderlos, garantizarlos y promoverlos (según la posición jurídica de cada quien y las exigencias que correspondan a cada derecho), independientemente de que su titular haya desplegado o no una conducta con ese propósito (por ejemplo, un juez está obligado a aplicarlos, sin importar que haya sido solicitado o no por la parte interesada, en el proceso judicial que conoce) $)^{5}$. Por si fuera poco - y sin agotar los múltiples aspectos de sus alcances y contenidoslos derechos fundamentales no solo son vistos actualmente como derechos de las personas naturales, sino también como derechos de las personas jurídicas, dependiendo del tipo de derecho de que se trate. iLa razón? Las personas jurídicas están integradas por personas naturales y la adscripción de derechos fundamentales en favor de aquellas redunda en la realización de los derechos en favor de estas (verbigracia, el debido proceso, la libertad contractual, la libertad de empresa, etc. $)^{6}$.

Como se ve, el panorama es sumamente amplio y rico para explorar sus consecuencias sobre el arbitraje, a partir de su recepción en la Constitución peruana. Ese, precisamente, es el objetivo que perseguimos en este trabajo. Evidentemente no pretendemos agotar todas las consecuencias posibles, pero sí ocuparnos de algunas de las más resaltantes para la operatividad del arbitraje. Para tal efecto haremos uso

4 Ver: ANSUÁtegul, Francisco Javier. «Las definiciones del Estado de derecho y los derechos fundamentales». Sistema, 158 (setiembre de 2000), pp. 91-114. Madrid.

5 Ver: PECES-BARBA, Gregorio. "De la función de los derechos fundamentales». Derechos sociales y positivismo jurídico. Escritos de filosofía jurídica y política. Cuadernos Bartolomé de las Casas, 11, Instituto de Derechos Humanos Bartolomé de las Casas, Universidad Carlos III de Madrid. Madrid: Dykinson, 1999, pp. 131-145.

6 En el derecho peruano, el Tribunal Constitucional ha establecido, a través de reiterada jurisprudencia, que las personas jurídicas privadas y los organismos públicos también pueden ser titulares de derechos fundamentales, según el tipo de derecho que se trate (ver, entre otras, la STC del 14 de agosto de 2002, fundamento 5, emitida en el expediente 0905-2001-AA/TC; STC del 13 de enero de 2005, fundamento 6, emitida en el expediente 2939-2004-AA/TC, y STC del 4 de agosto de 2006, fundamento 14, emitida en el expediente 4972-2006-PA/TC). 
de una doble perspectiva: por un lado describiremos cómo está instituido el arbitraje en la Constitución y en la jurisprudencia del Tribunal Constitucional peruano (además de dar cuenta de parte de su regulación legislativa), y por otro, prescribiremos cuáles son las consecuencias de su constitucionalización a partir de la relación que debe guardar con la Constitución, los derechos fundamentales y el Estado de derecho ${ }^{7}$. Con ese fin haremos uso de herramientas conceptuales propias de la teoría del derecho y de la teoría de la justicia, pero también de la dogmática jurídica en lo que corresponda ${ }^{8}$.

\section{ARBITRAJE Y CONSTITUCIÓN}

A partir de su calificación textual como «jurisdicción independiente» - que efectúa el artículo 139, inciso 1, de la Norma Fundamentalel Tribunal Constitucional ha señalado que «nuestro ordenamiento constitucional consagra la naturaleza excepcional de la jurisdicción arbitral, lo que determina que, en el actual contexto, el justiciable tenga la facultad de recurrir ante el órgano jurisdiccional del Estado para demandar justicia, pero también ante una jurisdicción privada»?

Pero ies esto correcto? ¿Es el arbitraje una jurisdicción especial de naturaleza privada? Si se pretende responder sobre la base de la terminología utilizada por el texto constitucional, habría que responder que sí (no se puede soslayar el hecho de que la Constitución utiliza la palabra «jurisdicción» para referirse al arbitraje), pero el empleo de una determinada locución no es suficiente para definir correctamente una categoría jurídica. A modo de ejemplo, la propia Constitución habla de «recurso de amparo» cuando en realidad el amparo no es un recurso - en nuestro sistema - sino un proceso (una cosa es el recurso, como especie de los medios impugnatorios, y otra el proceso, como mecanismo de composición de conflictos donde se interponen recursos).

7 Aquí utilizamos el término «prescriptivo» para identificar el tipo de discurso con el que se elabora un concepto o un modelo teórico. Es un sentido similar al otorgado por Carlos Santiago Nino cuando se ocupa de distinguir los tipos de discursos para referirse luego a la conexión entre derecho y moral, derecho y política. Se dice que un discurso puede ser prescriptivo, descriptivo o mixto. El discurso descriptivo se ocupa de lo que es algo en la realidad, de explicar, designar o utilizar situaciones de hecho $\sin$ formular propuestas o valoraciones normativas. El discurso prescriptivo no describe lo que es, sino que postula lo que debería ser, lo que sostiene puede no existir en la realidad, pero es muy útil para procurar su transformación. El discurso mixto resulta de una combinación de ambos, con el acento puesto en un tipo u otro, de ser el caso (Cf. del mencionado autor: Derecho, moral y política. Una revisión de la teoría general del derecho. Ariel Derecho. Barcelona: Ariel, 1994, pp. 41-42).

8 Con el nombre de "teoría de la justicia» se hace referencia a aquella parte de la Filosofía que, en un sentido general, se ocupa de estudiar las condiciones, características y estructuras que debe presentar una sociedad para que sea considerada justa, y en un sentido particular, a las que debe cumplir un derecho para ser reconocido como justo. Ver: VAN PARIJS, Philippe. ¿Qué es una sociedad justa? Introducción a la práctica de la filosofía política (1991). Traducción de Juana A. Bignozzi. Barcelona: Ariel, 1993, у Bоввіо, Norberto. "Filosofía del derecho y teoría general del derecho». En Contribución a la teoría del derecho. Serie de Derecho, edición a cargo del profesor Ruiz Miguel. Madrid: Debate, 1990, p. 88.

9 STC del 28 de febrero de 2006, fundamento 7, emitida en el expediente 6167-2005-PHC/TC. Las cursivas son nuestras. 
Debe acudirse entonces a los elementos que definen la jurisdicción y, a partir de allí, verificar si el arbitraje presenta o no esas características para determinar si puede ser calificado como jurisdicción. Una vez más se confirma que la concepción influye en el concepto ${ }^{10}$.

En efecto, si seguimos una teoría procesal clásica, advertimos que la jurisdicción —en términos amplios- requiere los siguientes requisitos para existir como tal: (i) ser una función que ejerce un tercero; (ii) para resolver o prevenir un conflicto intersubjetivo de intereses; (iii) a través de una decisión impuesta y vinculante para las partes, susceptible de adquirir la autoridad de cosa juzgada, y (iv) que pueda ejecutarse de manera forzosa por el propio tercero que la emitió, sin necesidad de contar con un acuerdo de las partes para que ello ocurra (bastará con que cualquiera de ellas lo solicite) ${ }^{11}$.

¿Cumple el arbitraje con todas estas características? No, solo con algunas de ellas. Aunque el inciso 1 del artículo 59 de la Ley de Arbitraje (en adelante, LA) señale que «todo laudo es definitivo, inapelable y de obligatorio cumplimiento desde su notificación a las partes», y el inciso siguiente añada que «el laudo produce efectos de cosa juzgada», su artículo 62 y siguientes contemplan la posibilidad de que el laudo - ese mismo laudo que supuestamente había adquirido la autoridad de cosa juzgada - pueda ser revisado por el Poder Judicial a través del recurso de anulación ${ }^{12}$.

Esto hace que la calidad de cosa juzgada que le atribuye la ley arbitral no se configure con su sola emisión (o, si se prefiere, con su notificación), pues al ser susceptible de un recurso de anulación, el laudo no gozaría todavía del carácter de «no revisable» que caracteriza a la cosa juzgada (el otro es la inmutabilidad). Por otro lado, el árbitro tampoco goza del imperio para ejecutar forzosamente y por sí mismo (es decir, sin que medie acuerdo de las partes) sus propias resoluciones. Cuando estas requieran ser ejecutadas coactivamente deberá acudir al Poder Judicial

10 La concepción es la perspectiva epistemológica o filosófica con la que nos aproximamos metodológicamente al objeto de estudio; nos permite estudiarlo, analizarlo, formular propuestas teóricas y, en general, tener una idea acerca de él. El concepto es la determinación de lo que el objeto de estudio es o puede llegar a ser, de aquello para lo cual sirve. Dependiendo del tipo de concepción que se utilice, se tendrá un concepto u otro del objeto de estudio.

11 Cf.: Monroy, Juan. Introducción al proceso civil. T. I. Santa Fe de Bogotá: Temis - De Belaunde \& Monroy, 1996, pp. 227-229.

12 Más allá de las discusiones que se pueden suscitar en el ámbito académico, nuestro Tribunal Constitucional ha establecido que, en nuestro ordenamiento jurídico, el llamado recurso de anulación del laudo tiene naturaleza recursiva, constituyendo una extensión del procedimiento arbitral, y no una demanda que origine un proceso distinto del arbitraje. Lo expresa así: «el recurso de anulación establecido en el artículo 61 de la Ley General de Arbitraje 26572 [entonces vigente y similar a la actual] (como también el recurso de apelación, si ese fuera el caso) no constituye, stricto sensu, un nuevo proceso judicial, sino parte integrante y residual del proceso arbitral seguido inicialmente ante el Tribunal Arbitral» (STC de 11 de diciembre de 2006, fundamento 10, emitida en los expedientes acumulados 6149-2006-PA/TC y 6662-2006-PA/TC). 
para que ordene su ejecución forzada, al contar este con el imperio del Estado para lograr ese objetivo (artículos 67 y 68 de la LA) ${ }^{13}$.

En suma, en la medida que el laudo arbitral no es susceptible de alcanzar - en sentido estricto - la autoridad de cosa juzgada, y en tanto los árbitros no cuentan con el imperio del Estado para ejecutar por sí mismos y de manera coactiva sus decisiones, al arbitraje le faltan dos de las características necesarias para ser calificado como jurisdicción.

Podría alegarse que no tenemos por qué seguir una concepción procesal clásica para definir la jurisdicción, sino asumir un planteamiento más flexible. De hecho, el Tribunal Constitucional lo hace para comprender en ella al arbitraje, cuando dice: «El ejercicio de la jurisdicción implica cuatro requisitos, a saber: a) conflicto entre las partes, b) interés social en la composición del conflicto, c) intervención del Estado mediante el órgano judicial, como tercero imparcial, y d) aplicación de la ley o integración del derecho» (como se puede ver, esta concepción no hace referencia a la cosa juzgada ni al imperio estatal para ejecutar las decisiones), y sobre esa base concluir: "Qué duda cabe, que prima facie la confluencia de estos cuatro requisitos definen la naturaleza de la jurisdicción arbitral, suponiendo un ejercicio de la potestad de administrar justicia» ${ }^{14}$.

Sin embargo, esta flexibilización del concepto de jurisdicción tiene un problema: con ella cualquier órgano administrativo, o cualquier sujeto privado, que resuelva o prevenga un conflicto intersubjetivo aplicando normas jurídicas, mediante una decisión que vincule a las partes y sea de interés social, será jurisdicción. Así, en ese supuesto ejercerían jurisdicción el tribunal privado de una asociación deportiva de fútbol

LA CONSTITUCIONALIZACIÓN DEL ARBITRAJE EN EL PERÚ: ALGUNAS CONSIDERACIONES EN TORNO A LA RELACIÓN DEL ARBITRAJE CON LA CONSTITUCIÓN, LOS DERECHOS

FUNDAMENTALES Y EL ESTADO DE DERECHO

CONSTITUTIONALIZATION OF ARBITRATION IN PERU: SOME CONSIDERATIONS AROUND RELATIONSHIP AMONG ARBITRATION, CONSTITUTION, FUNDAMENTAL RIGHTS AND RULE OF LAW

13 Art. 67 de la LA.- «Ejecución arbitral:

1. A solicitud de parte, el tribunal arbitral está facultado para ejecutar sus laudos y decisiones, siempre que medie acuerdo de las partes o se encuentre previsto en el reglamento arbitral aplicable.

2. Se exceptúa de lo dispuesto en el numeral anterior el caso en el cual, a su sola discreción, el tribunal arbitral considere necesario o conveniente requerir la asistencia de la fuerza pública. En este caso, cesará en sus funciones sin incurrir en responsabilidad y entregará a la parte interesada, a costo de esta, copia de los actuados correspondientes para que recurra a la autoridad judicial competente a efectos de la ejecución».

Art. 68 de la LA.- «Ejecución judicial:

1. La parte interesada podrá solicitar la ejecución del laudo ante la autoridad judicial competente acompañando copia de este y de sus rectificaciones, interpretaciones, integraciones y exclusiones $y$, en su caso, de las actuaciones de ejecución efectuada por el tribunal arbitral.

2. La autoridad judicial, por el solo mérito de los documentos referidos en el numeral anterior, dictará mandato de ejecución para que la parte ejecutada cumpla con su obligación dentro de un plazo de cinco días, bajo apercibimiento de ejecución forzada.

3. La parte ejecutada solo podrá oponerse si acredita con documentos el cumplimiento de la obligación requerida o la suspensión de la ejecución conforme al artículo 66. La autoridad judicial dará traslado de la oposición a la otra parte por el plazo de cinco días. Vencido este plazo, resolverá dentro de los cinco días siguientes. La resolución que declara fundada la oposición es apelable con efecto suspensivo.

4. La autoridad judicial está prohibida, bajo responsabilidad, de admitir recursos que entorpezcan la ejecución del laudo».

14 STC del 28 de febrero de 2006, fundamento 8, emitida en el expediente 6167-2005-PHC/TC. 
que sanciona las faltas cometidas por los jugadores en un partido, hasta el tribunal fiscal que examina las controversias entre la administración tributaria y los particulares.

El problema de esta concepción para nuestro sistema es que la Constitución peruana señala que la jurisdicción es una sola y se ejerce de manera exclusiva: «No existe ni puede establecerse jurisdicción alguna independiente», salvo las excepciones que la propia Constitución contempla, dentro de las cuales no se encuentran la justicia administrativa ni los órganos sancionadores de naturaleza privada (artículo 139, inciso 1).

¿Qué es entonces el arbitraje? Un mecanismo de justicia privada donde el conflicto se resuelve o se evita a través de la decisión de un tercero, elegido directa o indirectamente por las partes, que además de ser vinculante para estas es susceptible de ser ejecutado con el auxilio de los órganos jurisdiccionales del Estado. Es verdad que, en un esfuerzo por superar el problema mencionado, no faltan quienes denominan al arbitraje como un «equivalente» de jurisdicción, una «cuasi jurisdicción» o una jurisdicción en sentido «impropio», para distinguirla de los órganos jurisdiccionales del Estado que la ejercen en sentido «propio» ${ }^{15}$. Lo mejor, sin embargo, es calificarla como un mecanismo de justicia privada para evitar confusiones que pueden desfigurar alguna de estas instituciones.

No se trata de una simple exquisitez teórica sino de una precisión conceptual que tiene implicancias prácticas muy relevantes. Pensemos, por ejemplo, en las distintas consecuencias que se derivarían si se considerara que los árbitros ejercen jurisdicción, de manera similar a los jueces del Poder Judicial, frente a la consideración de que los árbitros solo imparten, nada más y nada menos, que justicia privada. Habría, por lo menos, diferencias importantes en la manera de configurar las relaciones de colaboración entre tales operadores. En el primer caso las relaciones serían más simétricas o paritarias, en términos de complementariedad y coordinación; en el segundo, más asimétricas o de sujeción, teniendo en cuenta que solo los jueces, y no los árbitros, serían quienes ejerzan jurisdicción.

La actual Ley de Arbitraje parece instituir, sin embargo, una tercera alternativa, al inclinar la balanza a favor del arbitraje. Prueba de ello son las normas que regulan la colaboración judicial en la actuación de los medios probatorios y la ejecución de las medidas cautelares dictadas en un arbitraje. Así, el artículo 45.3 de la LA establece que:

[...] a menos que la actuación de la prueba sea manifiestamente contraria al orden público o a leyes prohibitivas expresas, la autoridad

15 Cf.: CRemades, Bernardo. «El arbitraje en la doctrina constitucional española». Lima Arbitration, 1, 2006, pp. $185-220$. 
judicial competente se limitará a cumplir, sin demora, con la solicitud de asistencia [del tribunal arbitral], sin entrar a calificar acerca de su procedencia y sin admitir oposición o recurso alguno contra la resolución que a dichos efectos dicte.

Y el artículo 48.2 de la misma LA agrega:

En los casos de incumplimiento de la medida cautelar [emitida por un tribunal arbitral] o cuando se requiera de ejecución judicial, la parte interesada recurrirá a la autoridad judicial competente, quien por el solo mérito de las copias del documento que acredite la existencia del arbitraje y de la decisión cautelar, procederá a ejecutar la medida sin admitir recursos ni oposición alguna.

iCuidado! Estas disposiciones podrían vulnerar «la independencia en el ejercicio de la función jurisdiccional», que es una garantía que la Constitución otorga a todos los jueces de la República (artículo 139, inciso 2). Para evitar una interpretación o aplicación inconstitucional de los citados artículos de la ley, deberán ser armonizados con los principios y derechos de la Constitución.

Anotado este debate conceptual e identificadas algunas de sus consecuencias prácticas, cabe preguntarse, iqué aporta a la institución arbitral el hecho de que haya sido recogida por la Constitución? Definitivamentelaconvierte en un institutojurídicoconstitucionalmente protegido $\mathrm{o}$, en términos de la dogmática constitucional, en una «garantía institucional»; es decir, en un principio jurídico que, sin ser un derecho subjetivo y, por tanto, un derecho fundamental, cuenta con eficacia jurídica reforzada ${ }^{16}$.

Esto significa, según el Tribunal Constitucional, que posee «un núcleo o reducto indisponible por el legislador, de tal manera que ha de ser preservado en términos reconocibles para la imagen que de la misma tiene la conciencia social en cada tiempo y lugar, además de estar blindada contra una reforma legislativa [...] que la anule o la vacíe de contenido», lo que no excluye la posibilidad de que el legislador pueda legislar razonablemente sobre la garantía institucional, pues «requiere configuración legal, que se convertirá en la fuente normativa vital para delimitar su contenido protegido» ${ }^{17}$.

Dicho esto, y añadiendo los aportes hechos por la teoría del derecho, el arbitraje aparece entonces como un instituto constitucionalmente protegido, de tal suerte que el legislador tiene el deber de desarrollar

16 Ver: BAÑO LEÓN, José María. «La distinción entre derecho fundamental y garantía institucional en la Constitución española». Revista Española de Derecho Constitucional, 24, año 8 (setiembrediciembre de 1988), pp. 155-179. Centro de Estudios Constitucionales, Madrid.

17 STC del 27 de mayo de 2013, fundamento 83, emitida en el expediente 001-2013-PI/TC.

LA CONSTITUCIONALIZACIÓN DEL ARBITRAJE EN EL PERÚ: ALGUNAS CONSIDERACIONES EN TORNO A LA RELACIÓN DEL ARBITRAJE CON LA CONSTITUCIÓN, LOS DERECHOS FUNDAMENTALES y EL ESTADO DE DERECHO

CONSTITUTIONALIZATION OF ARBITRATION IN PERU: SOME CONSIDERATIONS AROUND RELATIONSHIP AMONG ARBITRATION, CONSTITUTION, FUNDAMENTAL RIGHTS AND RULE OF LAW 
su contenido, pero cuidando de no vulnerar aquellos elementos indispensables sin los cuales el arbitraje se convertiría en algo distinto o no podría alcanzar sus fines. Por lo tanto, cualquier regulación del arbitraje deberá ser razonable en parámetros constitucionales; esto es, deberá perseguir un fin constitucionalmente legítimo y resultar proporcional. El fin no será legítimo si la regulación pretende limitar el arbitraje en aras de realizar un derecho o bien jurídico infraconstitucional. La regulación no será proporcional si al limitar el arbitraje existe otra medida menos gravosa, o la medida empleada es inadecuada o inútil para conseguir el fin perseguido, o no hay una adecuada ponderación entre la limitación que se cause al arbitraje y el fin que pretenda alcanzarse ${ }^{18}$.

$\mathrm{Al}$ ser una norma constitucional, la garantía institucional del arbitraje también es un parámetro de validez jurídica de la mayor jerarquía: toda norma que vulnere su contenido será inválida. Esta jerarquía constitucional hace que las normas jurídicas relacionadas con el arbitraje deban ser creadas, interpretadas y aplicadas de tal manera que maximicen la virtualidad del arbitraje, siempre — y esto es muy importante- en armonía con las demás normas que mantienen con el arbitraje relaciones de coordinación y complementariedad en el ordenamiento jurídico (es el caso de los derechos fundamentales y de los demás bienes jurídicos constitucionalmente protegidos). No olvidemos que las normas jurídicas no están aisladas, incluyendo las constitucionales, razón por la cual toda interpretación atomista se encuentra proscrita: las normas jurídicas deben ser interpretadas de manera sistemática, teniendo en cuenta los diversos criterios con los que se relacionan.

Por último $-\mathrm{y}$ sin que eso signifique agotar todas las consecuencias de su constitucionalización - debe existir un adecuado mecanismo de tutela procesal para hacer frente a las amenazas o lesiones que pueda sufrir el arbitraje. Esto incluye una adecuada protección en favor de los derechos, principios y demás garantías que concurren a configurar la institución arbitral o se relacionan con ella.

\section{ARBITRAJE Y DERECHOS FUNDAMENTALES}

El arbitraje se encuentra vinculado con los derechos fundamentales. Es imposible que no lo esté, porque desde el momento en que afirmamos que el derecho es un sistema, todas sus normas se encuentran relacionadas entre sí —en términos de complementariedad, jerarquía, coordinación,

\footnotetext{
18 Ver: BeRNAL PULIDO, C. El principio de proporcionalidad y los derechos fundamentales. Madrid: Centro de Estudios Políticos y Constitucionales, 2003; GaVARA DE CARA, J. C. Derechos fundamentales y desarrollo legislativo. Madrid: Centro de Estudios Constitucionales, 1994; MEDINA GUERRERO, M. La vinculación negativa del legislador a los derechos fundamentales. Madrid: McGraw-Hill, 1996, y CARRAsco PeRERA, A.: «El juicio de razonabilidad en la justicia constitucional». Revista Española de Derecho Constitucional, 11, pp. 39 y ss.
} 
etcétera - para que el derecho pueda cumplir sus fines. En un derecho entendido como sistema, ninguna norma o instituto jurídico se encuentra aislado de los demás, sino que se influyen recíprocamente ${ }^{19}$. Como el arbitraje y los derechos fundamentales son elementos normativos del mismo sistema, es inevitable que guarden relaciones normativas entre sí, propias de ese sistema.

Más aún, debido a que en el derecho peruano el arbitraje y los derechos fundamentales cuentan con similar recepción en el texto constitucional, sus relaciones se presentan en términos de coordinación y complementariedad, mas no de jerarquía o subordinación. Esto no excluye que las normas arbitrales en especial $-\mathrm{y}$ todas las normas jurídicas en general - deban ser creadas, interpretadas y aplicadas de tal manera que se maximice el contenido y la virtualidad de los derechos fundamentales. ¿Por qué razón? Porque estos derechos son instrumentos indispensables para que todo derecho que aspire a ser justo - como ocurre con el ordenamiento peruano- procure alcanzar su fin último: el desarrollo integral de todas las dimensiones del ser humano ${ }^{20}$. Una conclusión propia de una teoría de la justicia.

¿Rigen entonces los derechos fundamentales en el arbitraje? Por supuesto que sí. Sin embargo, no han faltado voces que rechazan esta afirmación bajo el argumento de que la virtualidad de los derechos fundamentales es una cuestión que debe asegurarse en el marco de las relaciones con el Estado, con el fin de que protejan a los particulares de los excesos que pueda cometer un poder exorbitante como el estatal, pero que no tendría sentido extenderla — por lo menos no de la misma manera - en el marco de las relaciones entre privados — como es el caso del arbitraje-, porque en estas esa disparidad desaparece, o por lo menos se ve atenuada por la autonomía de la voluntad. Una postura equivocada por varias razones.

19 El derecho de nuestro tiempo está formado por un conjunto de normas y subsistemas jurídicos, estructurados por el Estado bajo la idea de sistema; es decir, organizados mediante un haz de relaciones -como las de jerarquía, coordinación y complementariedad- que busca eliminar los vacíos y defectos normativos, así como las contradicciones internas que se puedan producir, con el propósito de garantizar - en alguna medida - su unidad, coherencia y plenitud. Tal característica hace que la creación, interpretación y aplicación de una norma jurídica, para ser válida, debe tener en cuenta esas relaciones: no contradecir las normas superiores y guardar armonía con las que mantiene otro tipo de vínculo dentro del ordenamiento jurídico. La estructura sistemática del derecho hace que la creación, interpretación y aplicación de una norma no deba ser aislada. No debe prescindirse de las demás, sino considerar aquellas otras con las que integra un subsistema jurídico o mantiene alguna relación, tanto desde la perspectiva de su adecuación lógica como desde su adecuación teleológica y valorativa (Cf.: BoBBıo, Norberto. Teoría general del derecho, 1960. Serie de Derecho, cuarta reimpresión a la primera edición de 1991, traducción de Eduardo Rozo Acuña. Madrid: Debate, 1996, pp. 165 y ss., y PRIETO SANCHís, Luis. Apuntes de teoría del derecho. Estructuras y Procesos, Serie Derecho. Madrid: Trotta, 2005, pp. 113-142).

20 Ver: Peces-Barba, Gregorio. La dignidad de la persona desde la Filosofía del Derecho (2002). Segunda edición, Cuadernos Bartolomé de las Casas, 26, Instituto de Derechos Humanos Bartolomé de las Casas, Universidad Carlos III de Madrid. Madrid: Dykinson, 2003, pp. 77-78. 
En efecto, la concepción de los derechos fundamentales hace bastante tiempo que superó aquella visión que los reducía a simples instrumentos de defensa frente al Estado. Hoy los derechos fundamentales son vistos, como ya se ha adelantado, como elementos esenciales de todo ordenamiento jurídico que aspira a realizar contenidos suficientes de justicia; es decir, como aquellos elementos normativos que, junto con las demás normas constitucionales, fundan todo el derecho, organizan las diversas esferas del poder - tanto público como privado- y orientan a la sociedad, en sus diversas manifestaciones y estructuras, hacia objetivos determinados (con el fin último de procurar el desarrollo integral de todos y cada uno de los seres humanos).

En ese sentido, junto con las demás normas constitucionales, los derechos fundamentales se constituyen en los principales criterios de validez de todo el ordenamiento jurídico, en normas esenciales vinculantes tanto para el Estado como para los particulares. Al ser elementos esenciales del ordenamiento, todo se construye sobre su base, de tal suerte que no puede haber ámbito del derecho donde los derechos fundamentales no extiendan su fuerza normativa, incluyendo el arbitraje. Lo reconoce el propio Tribunal Constitucional cuando dice: «Si bien la autonomía de la jurisdicción arbitral tiene consagración constitucional, no lo es menos que, como cualquier particular, se encuentra obligada a respetar los derechos fundamentales». Por tratarse de criterios de validez jurídica, el mismo Tribunal concluye: «Será nulo y punible todo acto que prohíba o limite al ciudadano el ejercicio de sus derechos, de conformidad con el artículo 31 in fine de la Carta Fundamental $»^{21}$.

En realidad, lo dicho para los derechos fundamentales y sus relaciones con el arbitraje vale también para este y sus relaciones con la Constitución. Lo recuerda el mismo Tribunal:

La Constitución es la norma de máxima supremacía en el ordenamiento jurídico y, como tal, vincula al Estado y la sociedad en general. De conformidad con el artículo 38 de la Constitución, «Todos los peruanos tienen el deber [...] de respetar, cumplir [...] la Constitución [...]». Esta norma establece que la vinculatoriedad de la Constitución se proyecta erga omnes, no solo al ámbito de las relaciones entre los particulares y el Estado, sino también a aquellas establecidas entre particulares.

Ello quiere decir que la fuerza normativa de la Constitución, su fuerza activa y pasiva, así como su fuerza regulatoria de relaciones jurídicas, se proyecta también a las establecidas entre particulares, aspecto denominado como la eficacia inter privatos o eficacia frente a terceros de los derechos fundamentales. En consecuencia, cualquier acto proveniente de una persona natural o persona jurídica de derecho 
privado que pretenda conculcar o desconocerlos, como el caso del acto cuestionado en el presente proceso, resulta inexorablemente inconstitucional ${ }^{22}$.

No debe perderse de vista que la visión de los derechos fundamentales desde el prisma de la autonomía de la voluntad es una concepción que obedece a una ideología liberal sobre la libertad, pero no la única concepción sobre ella. Otras concepciones son posibles, como las provenientes de la tradición republicana. Para el liberalismo, la libertad, conocida como «libertad negativa o libertad como no interferencia», consiste «en que todos los hombres no me impidan decidir como quiera»; es decir, aquí ser libre significa disfrutar de una capacidad de elección sin impedimento ni coerción ${ }^{23}$. Supone que cada individuo tenga la oportunidad de actuar sin que otros sujetos puedan oponerle obstáculos. El único límite es no afectar la libertad de otro.

En este esquema, el Estado aparece como un mal necesario y su actuación debe estar dirigida a proteger los ámbitos de libertad del individuo ${ }^{24}$. Los derechos fundamentales se presentan aquí como derechos de defensa a favor del individuo, como un cerco de no-interferencia frente al poder. Al Estado solo le compete una labor de «policía» o de protección de esos derechos, debiendo actuar con «neutralidad» frente a su ejercicio. Únicamente si los derechos son vulnerados, si se producen intromisiones ilegítimas en el ámbito de libertad de los individuos, se requiere la intervención del Estado. Fuera de ello, la actuación estatal es considerada, en cualquier caso, como una interferencia en el ámbito de libertad que requiere de justificación sobre la base de otros bienes y valores individuales distintos a la libertad misma.

Al suponer esta idea de libertad una serie de ámbitos de soberanía del individuo frente a lo colectivo, la regulación que válidamente pueda establecerse al ejercicio de los derechos fundamentales no puede justificarse —según esta concepción- en la protección de un interés común o de un bien jurídico colectivo, ya que ello supondría invadir, de manera ilegítima, las esferas de soberanía del individuo. Por esa misma razón, la regulación de los derechos fundamentales solo podría justificarse en la ponderación de intereses particulares y en ningún modo en el bien común o en intereses de tipo colectivo.

Tal idea de la libertad es rechazada por el republicanismo. Para esta tradición, la libertad no es la mera ausencia de interferencias, sino la ausencia de «interferencias no arbitrarias» o «libertad como no

LA CONSTITUCIONALIZACIÓN DEL ARBITRAJE EN EL PERÚ: ALGUNAS CONSIDERACIONES EN TORNO A LA RELACIÓN DEL ARBITRAJE CON LA CONSTITUCIÓN, LOS DERECHOS

FUNDAMENTALES Y EL ESTADO DE DERECHO

CONSTITUTIONALIZATION OF ARBITRATION IN PERU: SOME CONSIDERATIONS AROUND RELATIONSHIP AMONG ARBITRATION, CONSTITUTION, FUNDAMENTAL RIGHTS AND RULE OF LAW 
dominación» (incluso un republicanismo más exigente demandaría la ausencia de posibilidades o riesgos de interferencias arbitrarias). Si hay interferencia pero esta no resulta arbitraria, entonces - a diferencia de lo que propugna el liberalismo- para el republicanismo la libertad no habría sido vulnerada. «Hay interferencia sin pérdida alguna de libertad cuando la interferencia no es arbitraria y no representa una forma de dominación: cuando está controlada por los intereses y las opiniones de los afectados y es requerida para servir a esos intereses de manera conforme a esas opiniones» ${ }^{25}$.

¿Qué hace que un acto de interferencia sea arbitrario? Lo es cuando está sujeto a la mera subjetividad, decisión o juicio de quien efectúa la intervención, cuando « es elegido, o no, sin atender a los intereses o a las opiniones de los afectados $»^{26}$, entendiendo por afectados no a las personas individualmente consideradas sino principalmente al conjunto de la sociedad, o por lo menos a todos los grupos interesados. Para esta tradición, el Estado es el que posibilita la grandeza y el desarrollo de la comunidad, el que contribuye a que los individuos puedan perseguir libremente sus propios fines; por lo tanto, ya no estamos aquí ante un Estado que resulta una amenaza potencial contra la libertad del individuo (como ocurría en el liberalismo), sino ante un Estado llamado a posibilitar o garantizar su realización.

Esto implica que el Estado no debe tener una posición neutral frente a los derechos; antes bien, además de protegerlos, debe participar en su configuración, regulación y realización, teniendo en cuenta no solo el interés individual sino también el interés común, pues para el republicanismo los derechos no solo responden a un interés individual sino también a un interés de la comunidad. Por ese motivo, es posible regular válidamente su ejercicio en aras de proteger un interés común o un bien jurídico colectivo. Las cuestiones que se plantean en torno a los derechos fundamentales no son asuntos de exclusivo interés particular sino que interesan también a la comunidad.

Como se puede apreciar, en un planteamiento republicano los derechos fundamentales no deben ser vistos solamente desde el prisma de la autonomía de la voluntad, como si fueran cuestiones que solo importan al interés individual y que sus titulares pueden disponer libremente, sin tener en cuenta otras consideraciones. Para el republicanismo, los derechos fundamentales importan también al interés general, razón por la cual deben ser configurados en una concurrencia armoniosa de la libertad con otros valores superiores, como la igualdad, seguridad y solidaridad. En tal esquema, es imposible sostener que los derechos 
fundamentales no rijan el arbitraje o que las partes puedan decidir, válidamente, que estos no le resultan aplicables.

¿Y qué filosofía política está presente en la Constitución peruana: la liberal o la republicana? Para empezar, el artículo 43 de nuestra Constitución, concordado con su artículo 3, califica al Perú bajo la fórmula política del Estado social y democrático de derecho, y no bajo la fórmula del Estado liberal, con todas las consecuencias que eso significa ${ }^{27}$. Además, la tipología de derechos que recoge la Constitución revela que esta considera como fundamentales varios derechos de contenido igualitario que de ninguna manera serían considerados como fundamentales por un planteamiento liberal (como el derecho a la vivienda, a la educación, a la salud, etc.). Ello aunado con el hecho de que la Constitución armoniza estos derechos con otros bienes jurídicos constitucionalmente protegidos, sintonizando el interés individual con el interés general, permite concluir que la Constitución peruana se adscribe mejor a parámetros republicanos.

Una conclusión que, a propósito del arbitraje, armoniza con la jurisprudencia del Tribunal Constitucional cuando, al referirse al fundamento de la institución arbitral, sostiene:

Es justamente, la naturaleza propia de la jurisdicción arbitral y las características que la definen, las cuales permiten concluir a este Colegiado que no se trata del ejercicio de un poder sujeto exclusivamente al derecho privado, sino que forma parte esencial del orden público constitucional. La facultad de los árbitros para resolver un conflicto de intereses no se fundamenta en la autonomía de la voluntad de las partes del conflicto, prevista en el artículo 2, inciso 24, literal a, de la Constitución, sino que tiene su origen y, en consecuencia, su límite, en el artículo 139 de la propia Constitución. De allí que el proceso arbitral

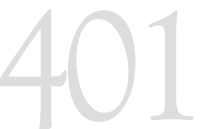

LA CONSTITUCIONALIZACIÓN DEL ARBITRAJE EN EL PERÚ: ALGUNAS CONSIDERACIONES EN TORNO A LA RELACIÓN DEL ARBITRAJE CON LA CONSTITUCIÓN, LOS DERECHOS

FUNDAMENTALES Y EL ESTADO DE DERECHO

CONSTITUTIONALIZATION OF ARBITRATION

IN PERU: SOME CONSIDERATIONS AROUND RELATIONSHIP AMONG ARBITRATION, CONSTITUTION, FUNDAMENTAL RIGHTS AND RULE OF LAW

27 Como bien explica nuestro Tribunal Constitucional, «el Estado social y democrático de derecho, como alternativa política frente al Estado liberal, asume los fundamentos de este, pero además le imprime funciones de carácter social. Pretende que los principios que lo sustentan y justifican tengan una base y un contenido material. $Y$ es que la libertad reclama condiciones materiales mínimas para hacer factible su ejercicio. Por ejemplo, la propiedad privada no solo debe ser inviolable, sino que debe ejercerse en armonía con el bien común y dentro de los límites de la ley. La seguridad e igualdad jurídicas requieren una estructura económica adecuada que haga posible estos principios». «La configuración del Estado social y democrático de derecho requiere dos aspectos básicos: la existencia de condiciones materiales para alcanzar sus presupuestos, lo que exige una relación directa con las posibilidades reales y objetivas del Estado y con una participación activa de los ciudadanos en el quehacer estatal, y la identificación del Estado con los fines de su contenido social, de forma tal que pueda evaluar, con criterio prudente, tanto los contextos que justifiquen su accionar como su abstención, evitando tornarse en obstáculo para el desarrollo social». En ese sentido, «la exégesis del régimen económico constitucional a la luz del principio del Estado social y democrático de Derecho (artículo 43 de la Constitución), que encuentra en el bien común (que es idéntico al interés de la sociedad) su ratio fundamental, bien puede ser traducida en la expresión [...]: «En materia económica es indispensable que toda actividad sea regida por la justicia y la caridad como leyes supremas del orden social. [Es necesario establecer] un orden jurídico, tanto nacional como internacional, que, bajo el influjo rector de la justicia social y por medio de un cuadro de instituciones públicas o privadas, permita a los hombres dedicados a las tareas económicas armonizar adecuadamente su propio interés particular con el bien común» (STC de 11 de noviembre de 2003, fundamento 12, emitida en el expediente 0008-2003-Al/TC). 
tiene una doble dimensión, pues, aunque es fundamentalmente subjetivo ya que su fin es proteger los intereses de las partes, también tiene una dimensión objetiva, definida por el respeto a la supremacía normativa de la Constitución, dispuesta por el artículo 51 de la Carta Magna. Ambas dimensiones, (subjetiva y objetiva) son interdependientes y es necesario modularlas en la norma legal y/o jurisprudencia. [...].

Así, la jurisdicción arbitral, que se configura con la instalación de un Tribunal Arbitral en virtud de la expresión de la voluntad de los contratantes expresada en el convenio arbitral, no se agota con las cláusulas contractuales ni con lo establecido por la Ley General de Arbitraje, sino que se convierte en sede jurisdiccional constitucionalmente consagrada, con plenos derechos de autonomía y obligada a respetar los derechos fundamentales. Todo ello hace necesario que este Tribunal efectúe una lectura iuspublicista de esta jurisdicción, para comprender su carácter privado, ya que, de lo contrario, se podrían desdibujar sus contornos constitucionales ${ }^{28}$.

Entre los derechos fundamentales que rigen el arbitraje se encuentra, indefectiblemente, el debido proceso $^{29}$. Lo ha explicado así el mismo Tribunal:

La naturaleza de jurisdicción independiente del arbitraje no significa que establezca el ejercicio de sus atribuciones con inobservancia de los principios constitucionales que informan la actividad de todo órgano que administra justicia, tales como el de independencia e imparcialidad de la función jurisdiccional, así como los principios y derechos de la función jurisdiccional. En particular, en tanto jurisdicción, no se encuentra exceptuada de observar directamente todas aquellas garantías que componen el derecho al debido proceso ${ }^{30}$.

En palabras del Tribunal Constitucional, y recogiendo doctrina consolidada, el debido proceso es aquel «derecho fundamental de carácter instrumental que se encuentra conformado por un conjunto de derechos esenciales [...] que impiden que la libertad y los derechos individuales sucumban ante la ausencia o insuficiencia de un proceso [...], o se vean afectados por cualquier sujeto de derecho (incluyendo al Estado) que pretenda hacer uso abusivo de estos». En otras palabras, como «el conjunto mínimo de elementos que deben estar presentes en

28 STC del 28 de febrero de 2006, fundamento 11, emitida en el expediente 6167-2005-PHC/TC.

29 Su calidad de derecho fundamental se encuentra reconocida en el artículo 3 de la Constitución peruana, concordado con el artículo 139 , inciso 3 , del mismo texto constitucional. Tal calidad hace que el debido proceso comparta las características que son comunes a los derechos fundamentales - con las consecuencias que se derivan de ello-, como el doble carácter que se reconoce a este tipo de derechos.

30 STC del 28 de febrero de 2006, fundamento 9, emitida en el expediente 6167-2005-PHC/TC. 
cualquier clase de proceso para hacer posible la aplicación de la justicia en el caso concreto» ${ }^{31}$.

A la par que en otros ordenamientos extranjeros, este derecho fundamental cuenta en el Perú con una doble manifestación: una procesal y otra sustancial, que ha llevado a hablar — con propósitos exclusivamente metodológicos - de un «debido proceso adjetivo o procesal» (conformado por el derecho de defensa, el derecho a probar, el derecho a un juez competente, independiente e imparcial, etc.) y de un «debido proceso sustantivo o sustancial» (que exige que todo acto, norma o decisión sea razonable, respetuoso de los derechos fundamentales y demás bienes jurídicos constitucionalmente protegidos), aunque se tratan de dos manifestaciones de un mismo derecho. Esta doble manifestación ha sido recogida por el Tribunal Constitucional, a través de una vasta jurisprudencia ${ }^{32}$.

En varias ocasiones ha puesto de relieve que «las dimensiones del debido proceso no solo responden a ingredientes formales o procedimentales, sino que se manifiestan en elementos de connotación sustantiva o material», al punto que «su evaluación no solo repara en las reglas esenciales con las que se tramita un proceso (juez natural, procedimiento preestablecido, derecho de defensa, motivación resolutoria, instancia plural, cosa juzgada, etc.), sino que también, y con mayor rigor, se orienta a la preservación de los estándares o criterios de justicia sustentables de toda decisión (juicio de razonabilidad, juicio de proporcionalidad, interdicción de la arbitrariedad, etc.) $»^{33}$.

No debe incurrirse en el error de pensar que todos y cada uno de los elementos del debido proceso resultan aplicables a todos los tipos de proceso, en particular al arbitraje. No olvidemos que estamos ante un derecho de carácter limitado, que se encuentra delimitado por su propio contenido, por las funciones que cumple y por las relaciones de coordinación y complementariedad que guarda con otros derechos fundamentales y con los demás bienes jurídicos constitucionalmente protegidos. Así, por ejemplo, la garantía de la pluralidad de instancia no parece exigible en el arbitraje (como tampoco lo es en el proceso

31 STC de 5 de julio de 2004, fundamento 22, emitida en el expediente 0090-2004-AA/TC. Cabe señalar que en la doctrina no hay uniformidad en el uso de las categorías «proceso" y «procedimiento». Hay quienes encuentran diferencias entre ellas, quienes les dan una acepción distinta, y quienes usan indistintamente ambos conceptos sin plantearse el tema de su diferencia. Por razones metodológicas, en este trabajo comprenderemos dentro del concepto de proceso el de procedimiento. Sin perjuicio de esta precisión metodológica, diremos que el concepto de "proceso» es muy relativo, en el sentido de que su definición depende del tratamiento que le brinde el ordenamiento jurídico de cada país. Para el autor de este trabajo solo en un proceso se ejerce función jurisdiccional, por ello solo tiene tal categoría el proceso judicial y el internacional. Allí donde no se ejerza jurisdicción no habrá proceso, sino simple procedimiento (de carácter administrativo, militar, arbitral, político o particular, siendo un ejemplo del penúltimo el llamado antejuicio político).

32 Entre ellas se encuentran las emitidas en los expedientes 090-97-AA/TC; 408-97-AA/TC; 04391999-AA/TC; 0993-1997-AA/TC; 0895-2000-AA/TC, y 0924-2000-AA/TC.

33 STC de 29 de agosto de 2006, fundamento 4, emitida en el expediente 3075-2006-PA/TC.

LA CONSTITUCIONALIZACIÓN DEL ARBITRAJE EN EL PERÚ: ALGUNAS CONSIDERACIONES EN TORNO A LA RELACIÓN DEL ARBITRAJE CON LA CONSTITUCIÓN, LOS DERECHOS

FUNDAMENTALES Y EL ESTADO DE DERECHO

CONSTITUTIONALIZATION OF ARBITRATION

IN PERU: SOME CONSIDERATIONS AROUND RELATIONSHIP AMONG ARBITRATION, CONSTITUTION, FUNDAMENTAL RIGHTS AND RULE OF LAW 
de inconstitucionalidad de las leyes), a menos que la norma que lo regule contemple instancias múltiples a las cuales acudir ${ }^{34}$.

Como regla general, podemos decir que, si bien el debido proceso resulta aplicable a cualquier tipo de proceso, algunos de sus elementos pueden no resultar exigibles en un determinado proceso - como es el caso del arbitraje - en la medida que razonablemente (lo que implica fin lícito y proporcionalidad) no resulten esenciales para que el debido proceso pueda cumplir con sus funciones y no pierda su naturaleza para convertirse en algo distinto. Dicho de otra manera, siempre resultarán exigibles $-\mathrm{y}$, por ende, aplicables en cualquier tipo de proceso, incluyendo el arbitraje - aquellos elementos del debido proceso que resulten razonablemente imprescindibles para que el inicio, desarrollo, conclusión y ejecución de un proceso pueda ser considerado justo (o, si se prefiere, para que los intereses jurídicos que protege resulten real, concreta y efectivamente protegidos). De no ser así, los procesos en mención resultarían inválidos.

Tampoco debe incurrirse en el error de equiparar debido proceso con las normas de la legislación procesal, especialmente del Código Procesal Civil. El primero es un derecho fundamental que cuenta con elementos exigibles independientemente de que se encuentren regulados o no por una ley procesal. Los segundos son cuerpos normativos que disciplinan los aspectos procedimentales de determinados procesos (penal, laboral, civil, etc.), por lo que no toda norma procesal integra el contenido del debido proceso y no todo elemento del debido proceso está regulado por la legislación procesal.

En el caso específico del arbitraje, no debe olvidarse que se trata de un mecanismo de justicia privada que responde a criterios distintos de los que informan los procesos judiciales o administrativos, razón por la cual debe cuidarse de no aplicar indebidamente al arbitraje criterios procesales que no responden a su naturaleza especial (artículo 34 de la LA) ${ }^{35}$. Todo ello, claro está, sin perjuicio de respetar el debido proceso, los derechos

34 Otro ejemplo, las medidas cautelares son institutos procesales que tienen por finalidad asegurar la eficacia de la resolución definitiva que se emita en un proceso. La urgencia de su dictado y la necesidad de evitar que el afectado con alguna medida realice actos que burlen su ejecución o impidan su cumplimiento, requieren que sean dictadas sin la notificación previa a la otra parte. Sin embargo, ello no significará que se haya afectado el debido proceso (por haberse afectado a una persona sin haberle dado la oportunidad previa de defenderse), pues, en tal caso, el ejercicio de su derecho de defensa queda postergado para después del dictado de la medida cautelar con la finalidad de asegurar la efectividad de la tutela que es también otro elemento integrante del debido proceso.

35 Art. 34 de la LA.- «Libertad de regulación de actuaciones:

1. Las partes podrán determinar libremente las reglas a las que se sujeta el tribunal arbitral en sus actuaciones. A falta de acuerdo o de un reglamento arbitral aplicable, el tribunal arbitral decidirá las reglas que considere más apropiadas teniendo en cuenta las circunstancias del caso.

2. El tribunal arbitral deberá tratar a las partes con igualdad y darle a cada una de ellas suficiente oportunidad de hacer valer sus derechos.

3. Si no existe disposición aplicable en las reglas aprobadas por las partes o por el tribunal arbitral, se podrá aplicar de manera supletoria, las normas de este decreto legislativo. Si no existe norma 
fundamentales y los demás bienes jurídicos constitucionalmente protegidos, en lo que corresponda.

\section{ARBITRAJE Y ESTADO DE DERECHO}

El concepto de Estado de derecho cuenta con un contenido básico esencial consolidado históricamente: se encuentra integrado por una serie de exigencias morales, políticas y jurídicas sin las cuales no puede haber Estado de derecho, independientemente de los modelos que se elijan o que han tenido una plasmación histórica. Por lo tanto, atendiendo al origen y desarrollo histórico que ha tenido este concepto, a pesar de que todo Estado genera derecho, presenta cierto grado de organización, se encuentra más o menos sometido a su propia legalidad, e incluso puede estar orientado a una determinada finalidad moral, no todo Estado es Estado de derecho. Para serlo debe cumplir, por lo menos, con las exigencias de su contenido básico esencial.

Si se tienen en cuenta los rasgos que configuran el paradigma histórico que da a luz a este concepto (el Estado liberal) y que se mantienen en sus otros modelos históricos (el Estado social y el Estado democrático de derecho), las exigencias de su contenido básico esencial se agrupan en torno a cuatro elementos, a saber: el imperio de la ley, la separación funcional del poder, la legalidad de la administración y el reconocimiento y eficacia de los derechos fundamentales ${ }^{36}$. Para efectos de este trabajo $-\mathrm{y}$ debido a sus límites materiales - nos detendremos en el primero de ellos.

El «imperio de la ley», como uno de los elementos configuradores del Estado de derecho, actúa sobre gobernantes y gobernados exigiendo que el poder político, en sus distintas manifestaciones, se origine y actúe sometido al derecho y de conformidad con él. No se trata de cualquier ley, sino que, en el contexto ideológico-político en que surge y se desarrolla el concepto de Estado de derecho que arranca del liberalismo y continúa con la democracia, pasando por los aportes republicanos, socialistas, etc., se trata de la que ha sido creada por el órgano popular representativo (Parlamento) como expresión de la voluntad general; es decir, con participación y representación de los integrantes del grupo social. Es la concretización racional de la voluntad general, manifestada a través de un órgano de representación libremente elegido.

aplicable en este decreto legislativo, el tribunal arbitral podrá recurrir, según su criterio, a los principios arbitrales así como a los usos y costumbres en materia arbitral.

4. El tribunal arbitral podrá, a su criterio, ampliar los plazos que haya establecido para las actuaciones arbitrales, incluso si estos plazos estuvieran vencidos".

36 Apoya esta afirmación, entre otros, Elías DíAz en su obra Estado de derecho y sociedad democrática. Cuadernos para el Diálogo. Madrid: Edicusa, 1966, pp. 18-28; también Eusebio FERNÁNDEZ, en su trabajo: «Hacia un concepto restringido de Estado de derecho». Sistema, Revista de Ciencias Sociales, 138 (mayo de 1997), pp. 101-114. Madrid.

LA CONSTITUCIONALIZACIÓN DEL ARBITRAJE EN EL PERÚ: ALGUNAS CONSIDERACIONES EN TORNO A LA RELACIÓN DEL ARBITRAJE CON LA CONSTITUCIÓN, LOS DERECHOS

FUNDAMENTALES Y EL ESTADO DE DERECHO

CONSTITUTIONALIZATION OF ARBITRATION IN PERU: SOME CONSIDERATIONS AROUND RELATIONSHIP AMONG ARBITRATION, CONSTITUTION, FUNDAMENTAL RIGHTS AND RULE OF LAW 
Aquí el término «ley» incluye tanto la ley ordinaria como la ley fundamental (Constitución), encontrándose la primera condicionada por y vinculada con esta última. Como consecuencia del «imperio de la ley», el poder no puede originarse ni actuar de manera arbitraria; de lo contrario, su origen o actuación — respectivamente- resultaría jurídicamente inválida, además de arriesgarse a ser políticamente inconveniente y moralmente injusta.

En el caso peruano, el Tribunal Constitucional ha relacionado está prohibición de arbitrariedad con la dimensión sustancial del debido proceso y la exigencia de razonabilidad, pues considera a «los principios de razonabilidad y proporcionalidad como componentes del debido proceso sustantivo, a cuyo respeto y observancia se encuentran obligadas todas las personas e instituciones, sean estas públicas o privadas» ${ }^{37}$. Sobre esa base, ha desarrollado el derecho a la razonabilidad de las decisiones, como expresión de la dimensión sustancial del debido proceso, sintetizándolo en la siguiente máxima: «El requisito de razonabilidad excluye la arbitrariedad. La idea que confiere sentido a la exigencia de razonabilidad es la búsqueda de la solución justa de cada caso» ${ }^{38}$.

Y iqué se entiende por arbitrariedad? El mismo Tribunal Constitucional lo explica:

El concepto de arbitrario apareja tres acepciones igualmente proscritas por el derecho: a) lo arbitrario entendido como decisión caprichosa, vaga e infundada desde la perspectiva jurídica; b) lo arbitrario entendido como aquella decisión despótica, tiránica y carente de toda fuente de legitimidad; y c) lo arbitrario entendido como contrario a los principios de razonabilidad y proporcionalidad jurídica. De allí que, desde el principio del Estado de derecho, surgiese el principio de interdicción de la arbitrariedad, el cual tiene un doble significado: a) En un sentido clásico y genérico, la arbitrariedad aparece como el reverso de la justicia y el derecho; b) En un sentido moderno y concreto, la arbitrariedad aparece como lo carente de fundamentación objetiva; como lo incongruente y contradictorio con la realidad que ha de servir de base a toda decisión. Es decir, como aquello desprendido o ajeno a toda razón de explicarlo ${ }^{39}$.

Aplicando estas ideas al arbitraje, se puede concluir que el «imperio de la ley», como elemento esencial de un Estado de derecho, en armonía con la dimensión sustancial del debido proceso, exige que la elección

37 STC de 28 de junio de 2004, fundamento 3f, emitida en el expediente 0199-2004-AA/TC. 38 STC del 5 de julio de 2004, fundamento 12, emitida en el Expediente 0090-2004-AA/TC.

39 lbid. Más adelante, en esta misma sentencia, en su fundamento 35, el mismo Tribunal Constitucional señalará: «Ahora bien, más allá de la convención doctrinaria que admite su autonomía como concepto, en puridad, la proporcionalidad es una modalidad más de la razonabilidad (razonabilidad instrumental)». 
y las actuaciones de cualquier autoridad arbitral no sean arbitrarias. Metodológicamente es posible agrupar tres tipos de supuestos en los cuales la decisión de una autoridad arbitral, emitida en el marco de un arbitraje, resulta arbitraria y, por tanto, vulneradora del «imperio de la ley» y de la dimensión sustancial del debido proceso, a saber:

- En primer lugar, la arbitrariedad que se produce cuando el árbitro sustenta su decisión en su simple voluntad o subjetividad -es decir, en lo que considera justo o injusto, válido o inválido-, y no en una derivación razonada del derecho aplicable, en relación con las circunstancias comprobadas del caso materia del arbitraje. Esto significa que la decisión del árbitro debe sustentarse en los valores, principios, derechos y demás normas jurídicas que concurren a la solución del caso concreto, así como en las circunstancias comprobadas de la causa. Incluso en el arbitraje de conciencia la opción por un resultado que el árbitro considere justo no debe ser una simple consecuencia de su subjetividad o de su particular apreciación de la vida, sino que debe ser una derivación razonada de elementos objetivos verificables y de la realidad social donde se produce o se quiere evitar el conflicto. En ese sentido ha dicho el Tribunal Constitucional peruano que el juzgador debe resolver «sin caer ni en arbitrariedad en la apreciación e interpretación del derecho, ni tampoco en subjetividades o inconsistencias en la valoración de los hechos del caso» ${ }^{40}$, pues «la inexistencia o inexactitud de los hechos y los argumentos de Derecho sobre los que [se...] funda una decisión discrecional constituye un error [...] determinante para la invalidez de la decisión» ${ }^{41}$.

- En segundo lugar, la arbitrariedad que se produce cuando la decisión del árbitro es producto de un razonamiento viciado, defectuoso, de tal suerte que lleva a conclusiones desacertadas, intolerables o contradictorias, al no encajar dentro del campo de lo opinable, sino dentro de lo ilógico, lo irreal o lo irracional, pues una decisión absurda no solo resulta descalificable como acto procesal, sino que además afecta la justicia del caso concreto (sea porque el resultado es injusto o porque el derecho a una resolución adecuadamente motivada y fundada de las partes resultó afectado). Uno de los supuestos que se presentan en este tipo de arbitrariedad es el de la decisión incongruente. Al respecto, precisa el mismo Tribunal que uno de los contenidos del debido proceso es el derecho a obtener del juzgador «una respuesta razonada, motivada y congruente» ${ }^{42}$, enseñando que este derecho «garantiza que el juzgador resuelva cada caso

LA CONSTITUCIONALIZACIÓN DEL ARBITRAJE EN EL PERÚ: ALGUNAS CONSIDERACIONES EN TORNO A LA RELACIÓN DEL ARBITRAJE CON LA CONSTITUCIÓN, LOS DERECHOS FUNDAMENTALES Y EL ESTADO DE DERECHO

CONSTITUTIONALIZATION OF ARBITRATION IN PERU: SOME CONSIDERATIONS AROUND RELATIONSHIP AMONG ARBITRATION, CONSTITUTION, FUNDAMENTAL RIGHTS AND RULE OF LAW 
concreto sin omitir, alterar o exceder las pretensiones formuladas por las partes ${ }^{43}$. Desarrollando más esta exigencia, agrega que el juzgador «no podría sustentar su decisión en hechos que no hayan sido alegados por las partes, ni resolver sobre pretensiones que no hayan sido formuladas (congruencia) $»^{44}$, concluyendo que un juzgador «no puede subrogarse en el papel de la parte y basar sus decisiones en hechos o pruebas que no hayan sido materia de contradicción oportuna» ${ }^{45}$. Como consecuencia de ello, destaca: «La infracción del deber de congruencia supone no solo la afectación del principio dispositivo [...], sino que a consecuencia de ello se puede afectar otros derechos constitucionalmente protegidos, verbigracia el derecho de defensa y, en determinadas ocasiones, el derecho a ser juzgado por un juez imparcial» ${ }^{46}$.

- En tercer lugar, la arbitrariedad se produce cuando las decisiones del árbitro no son conformes con la justicia material recogida en la Constitución, en la modalidad de derechos fundamentales u otros bienes jurídicos constitucionalmente protegidos. Esto se debe a que la superior fuerza normativa de estos elementos esenciales del ordenamiento no solo debe implicar que su eficacia alcance el trámite del arbitraje, sino también a las decisiones que en él se emitan. De lo contrario se llegaría al absurdo de aceptar que, a pesar de ser la base de todo el ordenamiento jurídico, el árbitro no se encuentra vinculado con esas normas constitucionales a la hora de tomar sus decisiones, contradiciendo así su naturaleza y superior fuerza normativa. En armonía con ello se ha expresado el Tribunal Constitucional peruano al decir que «el debido proceso en su dimensión sustancial quiere significar un mecanismo de control sobre las propias decisiones y sus efectos, cuando a partir de dichas actuaciones o decisiones se afecta de modo manifiesto y grave cualquier derecho fundamental», y por la misma razón, cualquier otro bien jurídico constitucionalmente protegido ${ }^{47}$.

En función de lo expuesto, podemos mencionar algunos ejemplos de arbitrariedad de las decisiones en sede arbitral. Así, son ejemplos de «arbitrariedad normativa» (es decir, de decisiones que no son el resultado de una derivación razonable del derecho aplicable), entre otros los siguientes ${ }^{48}$ : (i) las decisiones que desconocen, se apartan o arremeten contra la norma aplicable (contra legem), sin que se haya efectuado un control sobre su validez o constitucionalidad;

43 STC de 19 de junio de 2007, fundamento 9, emitida en el expediente 7022-2006-PA/TC

44 STC de 17 de setiembre de 2008, fundamento 6, emitida en el expediente 3151-2006-AA/TC.

45 Ibid., fundamento 13.

46 lbid., fundamento 5 .

47 STC de 14 de marzo de 2006, fundamento 30, emitida en el expediente 1209-2006-PA/TC.

48 Varios de estos ejemplos han sido tomados de: SAGÜÉs, Néstor P. Recurso extraordinario. Tomo II.

Buenos Aires: Depalma, 1984, pp. 613-690. 
(ii) las decisiones que no contienen un fundamento normativo, sino meras citas de normas; (iii) las decisiones basadas en normas inexactas o impertinentes; (iv) las decisiones basadas en la sola voluntad del juzgador; (v) las decisiones que aplican normas derogadas o no vigentes; (vi) las decisiones que invocan jurisprudencia no aplicable al caso concreto; (vii) las decisiones que interpretan la ley en forma defectuosa, irrazonable o distorsionante; (viii) las decisiones que consagran un formulismo manifiesto o formalidades ilógicas o irrazonables; (ix) las decisiones normativamente autocontradictorias, y (x) las decisiones que resultan incongruentes por no pronunciarse sobre lo pedido (incongruencia citra petita), por otorgar algo mayor a lo pedido (incongruencia ultra petita), por ordenar algo menor a lo pedido cuando tal posibilidad no sea jurídicamente posible (incongruencia infra petita), o por otorgar algo diferente a lo pedido (incongruencia extra petita).

En el caso de decisiones incongruentes, estas serán arbitrarias siempre que las normas que regulan el arbitraje donde se emitieron no permitan que el árbitro pueda emitir una decisión incongruente. Si lo permiten, el árbitro deberá anunciar previa y oportunamente a las partes tal posibilidad, con la finalidad de que estén en aptitud de defenderse, de probar, de alegar, y en general, de decir algo al respecto.

Como ejemplos de «arbitrariedad fáctica» (es decir, de decisiones que no evalúan adecuadamente los hechos o el material probatorio), podemos mencionar entre otros los siguientes ${ }^{49}$ : (i) las decisiones que prescinden de los hechos notorios o evidentes; (ii) las decisiones basadas en medios de prueba inexistentes o no incorporadas válidamente al arbitraje; (iii) las decisiones basadas en afirmaciones dogmáticas o genéricas de hecho; (iv) las decisiones que omiten examinar u omiten dar mérito o eficacia probatoria a un medio de prueba principal, decisivo y trascendente; (v) las decisiones que atribuyen al medio probatorio, o al hecho objeto de prueba, un alcance o sentido que le priva del que en verdad tenía; (vi) las decisiones que consideran los medios de prueba de manera superficial o poco seria, dando lugar a que la conclusión probatoria desemboque en un fundamento ilógico, desafortunado, aparente o contradictorio; (vii) las decisiones que fracturan el examen de los medios de prueba porque lejos de ser visualizados en conjunto, se los aisló y dejó como cabos sueltos, haciéndoles perder su eficacia; (viii) las decisiones que alteran la lógica interior y las derivaciones naturales de lo probado para acordarle una proyección concreta que es opuesta y que desvirtúa lo que verdaderamente resulta de las circunstancias comprobadas; (ix) las decisiones fácticamente autocontradictorias por una mala valoración de los hechos y/o del

LA CONSTITUCIONALIZACIÓN DEL ARBITRAJE EN EL PERÚ: ALGUNAS CONSIDERACIONES EN TORNO A LA RELACIÓN DEL ARBITRAJE CON LA CONSTITUCIÓN, LOS DERECHOS FUNDAMENTALES Y EL ESTADO DE DERECHO

CONSTITUTIONALIZATION OF ARBITRATION IN PERU: SOME CONSIDERATIONS AROUND RELATIONSHIP AMONG ARBITRATION, CONSTITUTION, FUNDAMENTAL RIGHTS AND RULE OF LAW 
material probatorio, y $(\mathrm{x})$ las decisiones que resultan contrarias a la ciencia, la técnica y las máximas de experiencia.

Como se puede advertir, la exigencia de la razonabilidad de las decisiones, o de la interdicción de la arbitrariedad, busca asegurar en todo proceso, incluyendo el arbitraje, la vigencia real y efectiva de los valores, derechos y demás normas que integran el ordenamiento jurídico, en armonía con la realidad social a la que pertenece y con las circunstancias comprobadas de la causa. Por lo tanto, una decisión que no respete esta exigencia no solo contraviene el «imperio de la ley», como componente esencial del Estado de derecho, sino también el derecho fundamental a un debido proceso, resultando, en consecuencia, inválida por inconstitucional.

\section{BREVE REFLEXIÓN FINAL}

Si queremos que el arbitraje continúe fortaleciéndose y desarrollándose en el Perú como un mecanismo adecuado y eficaz para la solución y prevención de los conflictos privados, debemos destacar la dimensión constitucional que le ha otorgado el derecho peruano. Eso implica profundizar en las relaciones que presenta con la Constitución, el Estado de derecho y los derechos fundamentales, tanto al momento de configurar su estatuto legislativo como al momento de llevar adelante los procesos arbitrales que resolverán los casos concretos a decidir.

Para tal efecto, el arbitraje no puede ser visto de una manera atomista, irrazonable o con un exceso ritual, sino de una manera sistemática, flexible y en armonía con los derechos fundamentales y los demás bienes jurídicos con los que guarda relaciones de coordinación y complementariedad en el ordenamiento jurídico. Así, desde el momento en que la Constitución considera al arbitraje como un mecanismo de justicia privada, complementaria a la jurisdicción estatal, bien puede decirse que existe un derecho a acudir al arbitraje como mecanismo de composición o prevención de conflictos, de libre disposición de las partes, que debe ser respetado, garantizado y tutelado. El Tribunal Constitucional lo ha reconocido - recordémoslo- en estos términos: «Nuestro ordenamiento constitucional consagra la naturaleza excepcional de la jurisdicción arbitral, lo que determina que, en el actual contexto, el justiciable tenga la facultad de recurrir ante el órgano jurisdiccional del Estado para demandar justicia, pero también ante una jurisdicción privada ${ }^{50}$.

Al mismo tiempo, no puede verse al arbitraje como algo que no es: un mecanismo de composición o prevención de conflictos que sustituye a 
los órganos jurisdiccionales del Estado. De allí que el mismo Tribunal ha precisado que:

[...] el arbitraje no puede entenderse como un mecanismo que desplaza al Poder Judicial, ni tampoco como su sustitutorio, sino como una alternativa que complementa el sistema judicial puesta a disposición de la sociedad para la solución pacífica de las controversias. Y que constituye una necesidad, básicamente para la solución de conflictos patrimoniales de libre disposición y, sobre todo para la resolución para las controversias que se generen en la contratación internacional ${ }^{51}$.

Si mantenemos el arbitraje dentro de estos cauces y potenciamos toda su virtualidad en armonía con los derechos y demás bienes jurídicos con los que guarda relaciones de coordinación y complementariedad, el arbitraje cumplirá cada vez mejor con sus funciones y contribuirá de una manera más destacada a alcanzar la paz social en justicia.

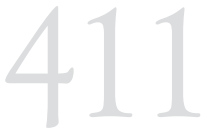

LA CONSTITUCIONALIZACIÓN DEL ARBITRAJE EN EL PERÚ: ALGUNAS CONSIDERACIONES EN TORNO A LA RELACIÓN DEL ARBITRAJE CON LA CONSTITUCIÓN, LOS DERECHOS FUNDAMENTALES YELESTADO DE DERECHO

CONSTITUTIO-

NALIZATION OF

ARBITRATION

IN PERU: SOME

CONSIDERATIONS

AROUND RELA-

TIONSHIP AMONG

ARBITRATION,

CONSTITUTION,

FUNDAMENTAL

RIGHTS AND RULE

OF LAW 